\title{
Impact of frequency of COPD exacerbations on pulmonary function, health status and clinical outcomes
}

This article was published in the following Dove Press journal:

International Journal of COPD

23 June 2009

Number of times this article has been viewed

\section{A Anzueto' \\ I Leimer ${ }^{2}$ \\ S Kesten ${ }^{3}$}

'The University of Texas Health Science Center at San Antonio and the South Texas Veterans Health Care System, Audie L Murphy Division, San Antonio, Texas, USA; ${ }^{2}$ Boehringer Ingelheim, Ridgefield, Connecticut, USA; ${ }^{3}$ Boehringer Ingelheim $\mathrm{GmbH}$, Ingelheim, Germany
Background: COPD exacerbations are responsible for the morbidity and mortality of this disease. The relationship between exacerbations and patient-related clinical outcomes is not clearly understood.

Methods: A retrospective analysis of two 1-year, placebo-controlled clinical trials with tiotropium $18 \mu \mathrm{g}$ daily was conducted to examine relationships between exacerbations and other clinical outcomes. The relationship between $\mathrm{FEV}_{1}$, St. George's Respiratory Questionnaire (SGRQ), and the transition dyspnea index (TDI) were examined based on the frequency of exacerbations $(0,1,2,>2)$.

Results: 921 patients participated in the trials (mean age 65 years, mean $\mathrm{FEV}_{1}=1.02 \mathrm{~L}(39 \%$ predicted). The percent change from baseline in $\mathrm{FEV}_{1}$ in the tiotropium group was $+12.6 \%$, $+12.0 \%,+2.1 \%$ and $+8.9 \%$; and in the placebo group was $-3.4 \%,-3.4 \%,-5.7 \%$ and $-6.7 \%$ for exacerbation frequencies of $0,1,2,>2$, respectively. Compared with baseline, the largest improvement in SGRQ occurred in patients with no exacerbations. In the placebo group, there was a significant association between an increased frequency of exacerbations and worsening SGRQ scores. A reduction in exacerbation rates of $4.4 \%$ to $42.0 \%$ such as that shown in this study cohort was associated with meaningful changes in questionnaire based instruments.

Conclusions: In the placebo-treated patients increased frequency of exacerbations was associated

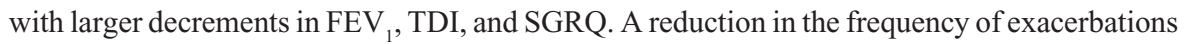
is associated with changes that are considered meaningful in these clinical outcomes.

Keywords: exacerbations, chronic obstructive pulmonary disease, $\mathrm{FEV}_{1}$, dyspnea, quality of life

\section{Introduction}

Exacerbations of COPD are known to be associated with increased morbidity and mortality and to have a significant socioeconomic impact. ${ }^{1-6}$ Patients with frequent exacerbations often experience impaired quality of life and a faster decline in lung function over time. ${ }^{7,8}$ Severe exacerbations that lead to hospitalization constitute a risk for mortality both during the hospitalization and during the subsequent year. ${ }^{9-11}$ Furthermore, the number of exacerbation may be the factor associated with increased mortality. ${ }^{12}$ In addition, exacerbations, including those requiring hospitalization, are the largest direct cost driver for the treatment of COPD in most countries. ${ }^{5,6,13}$ In the United States in 2000, direct expenditures for COPD were approximately US\$18 billion with almost $50 \%$ of the costs due to hospitalizations. ${ }^{5}$ While any reduction in frequency or duration of COPD exacerbations may be advantageous, it is important to consider the relationship of exacerbations to other variables of interest in patients with COPD.
Correspondence: Antonio Anzueto 7400 Merton Minter Blvd. (I I IE),

San Antonio, TX 78229, USA

$\mathrm{Tel}+\mathrm{I}(2 \mathrm{I} 0)$ 6I7-5256

Fax +I (2I0) 567-6677

Email anzueto@uthcsa.edu 
The threshold at which an intervention has a clinically meaningful effect is often referred to as the "minimal clinically important difference" (MCID) or the "minimal clinically important treatment effect" (MCITE). Jaeschke et al define the MCID as "the smallest difference in score in the domain of interest which patients perceive as beneficial and which would mandate, in the absence of troublesome side-effects and excessive cost, a change in the patient's management." ${ }^{14}$ For example, the St. George's Respiratory Questionnaire (SGRQ), used to measure health status in COPD patients, has been validated and is used extensively in COPD. For the SGRQ, a change of 4 units (from a 100 point scale) is considered the MCID. ${ }^{15,16}$ There is currently no MCID identified for a change in exacerbations of COPD; however, the occurrence of a single exacerbation is implicitly meaningful in terms of its clinical and cost impact and subsequent outcomes. It can therefore be argued that it is inappropriate to determine an MCID for exacerbations.

Interventions that reduce the risk of experiencing an exacerbation or reduce the frequency of exacerbations would be expected to have a consequent desirable impact on morbidity, health care costs and possibly on mortality. To date, several interventions have been proposed as potentially reducing exacerbations of COPD ${ }^{1}$ However, the recognition of a positive effect does not necessarily translate into a broad recommendation for maintenance use to prevent or reduce exacerbations. The effect must be balanced with the known safety profile of the intervention and the clinical relevance of the effect.

An analysis of trials in the clinical development of tiotropium allows the opportunity to examine the relationship between exacerbation and other relevant outcomes and whether the concept of an MCID could be applied to exacerbations of COPD. Tiotropium is an inhaled anticholinergic for the treatment of COPD that leads to a minimum of 24-hour bronchodilation with once-daily dosing. This sustained bronchodilation is thought to be a result of the prolonged dissociation half-life from the muscarinic $\mathrm{M}_{3}$ receptor (approximately 35 hours). ${ }^{17}$ Previously reported clinical trials of 1-year and of 6-months duration have demonstrated that tiotropium improves lung function, dyspnea, exercise tolerance and health status. ${ }^{18-22}$ In addition, tiotropium trials have shown consistent effects on reducing exacerbations of COPD. ${ }^{18-20,23,24}$ The objective of the present report is to use the data from two 1-year tiotropium vs placebo-controlled clinical trials ${ }^{18}$ to examine the relationship of frequency of exacerbations and other outcomes relevant to COPD such as the St. George's Respiratory Questionnaire (SGRQ), and the transition dyspnea index (TDI). Furthermore, we examined whether such outcomes can be used to explore the concept of a threshold for clinically meaningful reductions in exacerbation frequency.

\section{Methods}

Retrospective post-hoc analyses of two previously reported 1 -year placebo-controlled clinical trials with tiotropium $18 \mu \mathrm{g}$ daily ${ }^{18}$ were performed 1 ) to examine the relationship of exacerbation frequency with spirometry, dyspnea, and health status, and 2) to explore the potential for defining an MCID for exacerbations by examining changes in exacerbation frequency according to currently assumed MCID for measures of dyspnea and health status.

\section{Study design}

The trials used a randomized, double-blind and parallel-group design. Tiotropium was administered at $18 \mu \mathrm{g}$ once daily via the HandiHaler ${ }^{\circledR}$ device (Boehringer Ingelheim $\mathrm{GmbH}$ and Co. KG, Ingelheim, Germany) and the trials were conducted in 50 centers in the United States. ${ }^{18}$ All patients who participated in these trials were at least 40 years of age, had a diagnosis of COPD with a smoking history of at least 10 pack-years and had objective documentation of airflow limitation (forced expiratory volume in 1 second $\left[\mathrm{FEV}_{1}\right]<60$ to $65 \%$ predicted, $\mathrm{FEV}_{1} /$ forced vital capacity $[\mathrm{FVC}]<70 \%$ ). The major inclusion and exclusion criteria for the trials were designed to include patients with stable COPD, exclude those with asthma, and exclude those with potentially unstable, serious co-morbid conditions that would interfere with either the interpretation of the results or the ability of the patient to complete studies of 1 year duration.

During the treatment period, all patients who participated in these one-year studies, including those randomized to placebo, were permitted to take their previously prescribed respiratory medications for COPD with the exception of long-acting beta-adrenergic agonists (LABAs) and inhaled anticholinergic agents. All patients were provided with a short-acting beta-agonist (albuterol) to use as-needed for rescue relief of symptoms. Patients were permitted medications to treat exacerbations as medically indicated. Clinic visits were scheduled at 6 weeks, and on four other occasions (equally spaced) during the approximately 1-year treatment period. All patients signed written informed consent before any study procedures were performed. 


\section{Assessments}

The primary endpoint was morning pre-dose $\mathrm{FEV}_{1} \cdot{ }^{18}$ Other assessments (including dyspnea, as needed albuterol, health status and exacerbations) were secondary outcomes.

$\mathrm{FEV}_{1}$ and $\mathrm{FVC}$ were measured at clinic visits using calibrated spirometers and results were assessed in accordance with American Thoracic Society criteria. ${ }^{25}$

Dyspnea was assessed using the Baseline and Transition Dyspnea Index. ${ }^{26}$ The Dyspnea Index questionnaire consists of three domains (functional impairment, magnitude of task, and magnitude of effort). Scores from the three domains are summed to determine a focal score. This instrument was administered at baseline to determine the Baseline Dyspnea Index (BDI), an assessment of the baseline severity of dyspnea, and at defined intervals throughout the studies to determine the Transition Dyspnea Index (TDI), an assessment of change from baseline. A change of $\geq 1$ unit in the focal score was used to represent a clinically meaningful change. ${ }^{27,28}$

The St. George's Respiratory Questionnaire (SGRQ) was used as the disease specific measurement of health status. ${ }^{16}$ The SGRQ consists of a 76 item questionnaire divided into three domains (symptoms, activities, and impacts). The total score is a composite of the three domains. The SGRQ was administered at baseline and at intervals throughout each study. A change of $\geq 4$ units in the total score was used to represent a clinically meaningful change..$^{15,16}$

\section{Exacerbations of COPD}

Exacerbations were defined "as a complex of respiratory events (ie, cough, wheezing, dyspnea or sputum production) lasting $>3$ days. These events were generally treated with antibiotics and/or oral steroids" 18,19 and reported by the investigator as an adverse event.

\section{Data analysis}

Analyses used for primary and secondary outcomes have been previously reported. ${ }^{18}$ The statistical model used for measures of spirometry, dyspnea and SGRQ was the analysis of covariance with terms for treatment and center with baselines as covariates. All patients with a non-missing baseline and at least one non-missing post-baseline values were included in the analyses. This can result in different number of patients analyzed for the various outcomes. None of the analyses were corrected for multiple comparisons. The incidence of exacerbations and hospitalizations was analyzed using a logistic regression adjusting for extent of exposure. The number of exacerbations and hospitalizations was analyzed using the Wilcoxon-MannWhitney test. Statistical significance was defined as $P<0.05$.

\section{Analysis assessing the relationship}

\section{of exacerbations to other outcomes}

Multiple post-hoc analyses were conducted to explore associations of the occurrence of exacerbations or the frequency of exacerbations with other outcomes recorded as part of the clinical trials.

The categorization of patients into different frequencies of exacerbations $(0,1,2,>2)$ was determined without adjustment for patient exposure to treatment. Associations between exacerbation frequency with changes in $\mathrm{FEV}_{1}$ and changes in SGRQ scores over one year were tested using an analysis of covariance model with terms for treatment, categories and treatment categories interaction. Values are expressed as means \pm SE unless otherwise specified. Spearman's rank correlation coefficient was determined (with the corresponding $P$-value for testing difference from zero) for within group changes in $\mathrm{FEV}_{1}$ and SGRQ total and impacts scores to exacerbation frequency $(0,1,2,>2)$.

\section{Analysis exploring an MCID for exacerbations}

In an attempt to define a clinically meaningful reduction in exacerbations, the number of exacerbations per patient year was assessed according to categories of change in dyspnea (TDI focal score), and health status (SGRQ total score). Categories were defined based on the following assumed MCIDs: TDI focal score (1 unit), and SGRQ total score (4 units). For the TDI focal score, patients were divided into groups according to a change of $\leq-1,0$, or $\geq+1$ unit. For the SGRQ total score, patients were divided into groups according to a change of $\geq+4,0$ to $+4,0$ to -4 or $\leq-4$ units. In addition, to examine associations with corresponding MCIDs for other outcomes in a relatively stable population, the percent change in number of exacerbations per patient year was calculated for the placebo group according to shifts from one category of scores to another category for each instrument. Changes from baseline could not be assessed as there was no collection of the frequency of exacerbations in the period prior to randomization.

\section{Results}

A total of 921 patients with COPD were randomized into these trials, 550 of whom were treated with tiotropium. The mean age was approximately 65 years with approximately $65 \%$ being men. The mean $\mathrm{FEV}_{1}$ was $1.02 \mathrm{~L}$ (39\% predicted). There were no differences in exposure to study drug between tiotropium and placebo groups. Tiotropium was associated with improvements in lung function, dyspnea, and healthstatus and reduced the requirement for as-needed albuterol. 
These results are described in detail in a previous publication. ${ }^{18}$ Tiotropium was associated with a reduction in exacerbations and hospitalizations related to exacerbations. ${ }^{18}$

To examine the effect of exacerbations on other outcomes, the changes in $\mathrm{FEV}_{1}$, and SGRQ total scores were assessed according to frequency of exacerbations.

\section{Decline in lung function}

The mean baseline $\mathrm{FEV}_{1}$ in subgroups with exacerbation frequency of $0,1,2$, or $>2$ over the study period for tiotropium vs placebo were $1.06 \mathrm{~L}$ vs $1.05 \mathrm{~L}, 0.96 \mathrm{~L}$ vs $0.95 \mathrm{~L}, 0.90 \mathrm{~L}$ vs $0.88 \mathrm{~L}$, and $0.88 \mathrm{~L}$ vs $0.88 \mathrm{~L}$, respectively. Tiotropium improved mean $\mathrm{FEV}_{1}$ in patients in all categories of frequency of COPD exacerbations (Table 1). However, in the tiotropium group, increasing frequency of exacerbations was generally associated with a lower absolute degree of improvement (Table 1). With tiotropium, the percent change from baseline (calculated as percent of mean change from baseline versus mean baseline) in $\mathrm{FEV}_{1}$ was $+12.6 \%,+12.0 \%,+2.1 \%$ and $+8.9 \%$ for exacerbation frequencies of $0,1,2,>2$, respectively. The placebo group showed a reduction in $\mathrm{FEV}_{1}$ at all frequencies of COPD exacerbations. In the placebo group, increasing frequency of exacerbations was generally associated with a higher rate of decline over one year. In the placebo group, the percent change from baseline in $\mathrm{FEV}_{1}$ was $-3.4 \%,-3.4 \%,-5.7 \%$ and $-6.7 \%$ for exacerbation frequencies of $0,1,2,>2$, respectively. Confounding by the different baselines (ie,lower FEV ${ }_{1}$ with increased exacerbation frequency) cannot be ruled out. The correlation between changes in $\mathrm{FEV}_{1}$ and exacerbation frequency was $-0.131(P=0.003)$ in the tiotropium group and $-0.027(P=0.628)$ in the placebo group.

\section{Health status}

The SGRQ total scores were assessed according to frequency of exacerbations to allow examination of the association of exacerbations on health status. Despite the adverse effect

Table I Mean (SE) changes in $\mathrm{FEV}_{1}(\mathrm{~mL})$ in the tiotropium and placebo groups over I year according to exacerbation frequency

\begin{tabular}{|c|c|c|c|c|}
\hline \multirow[b]{2}{*}{$\begin{array}{l}\text { Exacerbation } \\
\text { frequency }\end{array}$} & \multicolumn{2}{|c|}{ Tiotropium $(n=5 \mid 8)$} & \multicolumn{2}{|c|}{ Placebo $(n=328)$} \\
\hline & $\mathbf{N}$ & $\Delta \mathrm{FEV}_{\mathrm{I}}(\mathrm{mL})$ & $\mathbf{N}$ & $\Delta \mathrm{FEV}_{1}(\mathrm{~mL})$ \\
\hline 0 & 327 & $+134(12)$ & 179 & $-36(16)^{*}$ \\
\hline 1 & 111 & $+115(20)$ & 92 & $-32(22)^{*}$ \\
\hline 2 & 44 & $+19(32)$ & 34 & $-50(37)$ \\
\hline$>2$ & 36 & $+78(36)$ & 23 & $-59(44)^{*}$ \\
\hline
\end{tabular}

$* P<0.05$ tiotropium vs placebo. of exacerbations, all mean SGRQ scores in tiotropium patients remained lower than baseline (ie, improved) for 1 year (Table 2). Compared with baseline, the largest improvement in mean SGRQ occurred in patients with no exacerbations; compared with placebo, the greatest benefit was noted in patients with the most frequent exacerbations. In the placebo group, there was an association between an increased frequency of exacerbations and worsening SGRQ scores. As with $\mathrm{FEV}_{1}$ decline, confounding by the different baselines (ie, lower $\mathrm{FEV}_{1}$ with increased exacerbation frequency) cannot be ruled out. The correlation between SGRQ impacts and total scores and exacerbation frequency in the tiotropium group was $0.011(P=0.805)$ and 0.049 $(P=0.271)$ respectively. The corresponding correlation coefficients in the placebo group were $0.116(P=0.037)$ and $0.150(P=0.007)$.

\section{Association of exacerbations to MCIDs for other clinical outcomes}

Frequencies of exacerbations per patient year were assessed in the tiotropium and placebo groups according to currently recognized MCIDs for dyspnea (TDI focal score), and healthstatus (SGRQ total score). Improvements in these instrument scores were associated with reductions in the frequency of exacerbations, with larger questionnaire score improvements associated with larger reductions in exacerbations (Table 3).

In considering whether the change equal to the MCID for one of the instruments (TDI $\geq 1$ unit, SGRQ $\leq 4$ units) can be associated to a corresponding change in the frequency of exacerbations, the placebo group serves as a relatively stable population who has not received a new intervention. The change in frequency of exacerbations was calculated for the placebo group according to shifts equal to the MCIDs in questionnaire scores.

A TDI focal score change of $\geq+1$ unit was associated with a $28.7 \%$ less exacerbations per patient year in mean frequency of exacerbations compared with those who had a change of 0 ; those who had a change of 0 had a $42.0 \%$ reduction in mean frequency of exacerbations compared with those who had a change of $\leq-1$ unit.

An SGRQ total score change of -4 units was associated with a $38.5 \%$ relative reduction in mean frequency of exacerbations compared with those who had a change of 0 to $\leq+4$ units; those who had a change of 0 to $<-4$ units had a $4.4 \%$ relative reduction in mean frequency of exacerbations compared with those who had a change of $\geq 4$ units.

The analysis suggests that a reduction in exacerbations can be examined in terms of changes associated with other 
Table 2 Mean (SE) changes in the St. Georges Respiratory Questionnaire total scores in the tiotropium and placebo groups over I year according to exacerbation frequency

\begin{tabular}{llllll}
\hline \multirow{2}{*}{$\begin{array}{l}\text { Exacerbation } \\
\text { frequency }\end{array}$} & \multicolumn{2}{l}{ Tiotropium $(\mathbf{n}=\mathbf{5}$ I6) } & & \multicolumn{2}{l}{ Placebo $(\mathbf{n}=\mathbf{3 2 4})$} \\
\cline { 2 - 3 } & $\mathbf{N}$ & Total score & & $\mathbf{N}$ & Total score \\
\hline 0 & 326 & $-4.0(0.7)$ & & 175 & $-1.5(0.9)^{* *}$ \\
$\mathrm{I}$ & $\mathrm{III}$ & $-2.7(1.1)$ & 92 & $0.9(1.2)^{* *}$ \\
2 & 44 & $-1.3(1.8)$ & 34 & $2.6(2.0)$ \\
$>2$ & 35 & $-3.4(2.0)$ & 23 & $5.3(2.5)^{* *}$ \\
\hline
\end{tabular}

$* * P<0.05$ tiotropium vs placebo.

meaningful outcomes. The analysis is limited by lower numbers in the various subgroups. A relative reduction in exacerbation rates of $4.4 \%$ to $42.0 \%$ such as that shown in this study cohort was associated with meaningful changes in questionnaire based instruments.

\section{Discussion}

We sought to examine the relationship of exacerbations and clinical outcomes. Furthermore, we wanted to evaluate if the clinical relevance of a reduction in exacerbations in patients participating in controlled clinical trials could be determined. In the present analysis the frequency of exacerbations was shown to be directionally associated with changes in spirometry, dyspnea, and health status of the patient's COPD. Our data suggest that reductions in the frequency of exacerbations rates of $4.4 \%$ to $42.0 \%$ were associated with meaningful changes in questionnaire based instruments.

Based on the significant health care costs, and increased morbidity and mortality related to exacerbations of COPD, ${ }^{1-4}$ it could be argued that any reduction in exacerbations is meaningful. Examination of the relationships of exacerbations with patient-related outcomes is worth in understanding the clinical impact of a reduction or increase in frequency of exacerbations. While the associations of exacerbations with other outcomes are recognized, it is not proven in a clinical trial that a change in the frequency of exacerbations has an impact on other outcomes that can be considered meaningful. Knowledge of such associations with exacerbations could help to determine the threshold at which a therapeutic intervention is warranted. For example, an extremely small (eg, 1\%) decrease in exacerbations may be statistically significant but not of sufficient clinical importance to justify prescription of an intervention based on costs, side effects and other considerations (ie, efficacy or lack of efficacy on other endpoints). In this study we are showing that the reduction of patient's COPD exacerbation is also associated with an impact in patient-related outcomes.
In the consideration of any analysis attempting to define clinically important changes, the definition of an exacerbation needs to be clear and regarded as meaningful. The specific definition of COPD exacerbations in published clinical trials has varied, although in general the definitions fall within the framework proposed by a consensus definition published in 2000 as follows: "a sustained worsening of the patient's condition, from the stable state and beyond normal day-to-day variations that is acute in onset and necessitates a change in regular medication in a patient with underlying COPD."29 The definition is consistent with the American Thoracic Society and European Respiratory Society definition published in $2004{ }^{30}$ and the revised GOLD statement. ${ }^{1}$ There are essentially three components of a definition for exacerbations: a) an implied minimal time frame of the event (ie, day-to-day), b) a degree of change in respiratory symptoms (ie, beyond normal variations, acute in onset), and c) a statement that an intervention is required (ie, change in regular medication).

There have been relatively few studies looking at the relationship between COPD exacerbations and quality of life in patients with COPD. Seemungal and colleagues showed that exacerbations were more frequent in patients with frequent previous exacerbations (odds ratio $=5.5, P=0.001$ ). Using the median number of exacerbations, patients were classified as infrequent exacerbators ( $0-2$ ) or frequent exacerbators (3-8). SGRQ total score was significantly worse in frequent exacerbators (mean difference 14.8, $P<0.001$ ). In multiple regression analyses, exacerbation frequency was strongly correlated with SGRQ total score and component scores. Conners and colleagues evaluated quality-of-life outcomes in their study of patients hospitalized with acute exacerbations of COPD. ${ }^{10}$ At 6 months patients were interviewed about their activities of daily living, and 54\% required assistance with at least one activity of daily living and $49 \%$ considered their health status to be fair or poor. No analysis was conducted on the relationship between readmissions and perceived quality of life.

Both of the aforementioned investigations support the concept that COPD exacerbations have a negative effect on quality of life in patients with COPD. This association suggests that quality of life is impaired not only in patients who are hospitalized for acute exacerbations of COPD, but also in patients who experience frequent exacerbations that are treated in the ambulatory care setting. Hence, while a survival benefit might be expected from a reduction in COPD exacerbations requiring hospitalization, an improvement in quality of life might be an anticipated outcome of a reduction in overall exacerbations, including those that do not require hospitalization. The present analysis corroborates the hypothesis that exacerbations 
Table 3 Number of exacerbations per patient year according to treatment group and end-of-treatment transition dyspnea index (TDI) focal score, and change from baseline in St. Georges Respiratory Questionnaire (SGRQ Ototal score)

\begin{tabular}{|c|c|c|c|c|c|c|c|c|}
\hline & \multicolumn{4}{|c|}{ Tiotropium } & \multicolumn{4}{|l|}{ Placebo } \\
\hline & $\mathbf{N}$ treated & No. of exacerbations & Patient years & Rate & $\mathbf{N}$ treated & No. of exacerbations & Patient years & Rate \\
\hline \multicolumn{9}{|l|}{$\Delta$ TDI } \\
\hline \multicolumn{9}{|c|}{ Focal score } \\
\hline$\leq-1$ & 81 & 88 & 63.0 & 1.40 & 80 & 91 & 60.5 & 1.50 \\
\hline 0 & 193 & 108 & 156.5 & 0.69 & 152 & 106 & 122.5 & 0.87 \\
\hline$\geq 1$ & 233 & 123 & 198.5 & 0.62 & 93 & 49 & 79.1 & 0.62 \\
\hline \multicolumn{9}{|l|}{$\triangle$ SGRQ } \\
\hline \multicolumn{9}{|c|}{ Total score } \\
\hline$\geq 4$ & 118 & 82 & 96.6 & 0.85 & 113 & 102 & 89.4 & 1.14 \\
\hline$\geq 0,<4$ & 65 & 39 & 51.2 & 0.76 & 48 & 33 & 37.8 & 0.87 \\
\hline$>-4,<0$ & 79 & 51 & 63.6 & 0.80 & 65 & 58 & 53.4 & 1.09 \\
\hline$\leq-4$ & 254 & 148 & 214.1 & 0.69 & 98 & 54 & 81.1 & 0.67 \\
\hline
\end{tabular}

impact health-related quality-of-life and demonstrates that interventions that reduce exacerbations are associated with improvements in quality of life.

Donaldson et al evaluated the relationship between exacerbation frequency and decline in lung function in 109 patients (mean age 68.1 years, mean $\mathrm{FEV}_{1} 1.00$ (0.7-1.3 L) recruited from outpatient clinics in the UK. ${ }^{31}$ The mean exacerbation rate was 2.92 exacerbations/year; patients with $\geq 2.92$ exacerbations per year were considered frequent exacerbators; those with $\leq 2.92$ exacerbations per year were considered infrequent exacerbators. $\mathrm{FEV}_{1}$ data were evaluated over 4 years in 16 frequent exacerbators compared with 16 infrequent exacerbators. In this subgroup, frequent exacerbators were younger (median age 61.6 vs 71.5 years, $P=0.03$ ) and a higher number of frequent exacerbators were current smokers ( $9 / 16$ vs $1 / 16$ respectively). The mean rate of decline in $\mathrm{FEV}_{1}$ in the total cohort was $36 \mathrm{~mL} /$ year. The mean rate of decline in $\mathrm{FEV}_{1}$ per year was greater in the frequent compared with infrequent exacerbators $(40.1 \mathrm{ml} /$ year vs $32.1 \mathrm{ml} /$ year, respectively, $P<0.05$ ). The present study supports the contention that exacerbations can accelerate the loss of lung function over time and suggests that such changes may possibly be modified by interventions reducing exacerbations; however, it is recognized that firm conclusions cannot be drawn from the present analysis given the relatively short time of study (1 year) and the retrospective nature of the analysis.

In considering an MCID for exacerbations, we recognize that the present retrospective analyses has several limitation and do not establish a precise association of the frequency or severity of exacerbations with a MCID in a given dyspnea or health status instrument. A limitation to the present analysis is that there was no adjustment for potential confounders such as $\mathrm{FEV}_{1}$. In addition, based on the published literature, there is no precedent for establishing a clinically meaningful reduction in COPD exacerbations and it is not the purpose of the present analyses to state that this should be a prerequisite for evaluating interventions. It should also be noted that MCID metrics designed from health status are not generally considered appropriate to apply to a clinical outcome such as exacerbations. MCID is a metric established to confer meaning to patient-reported outcome scales that have no intrinsic meaning (eg, quality of life scales from 0 to 1 ). It is reasonable to consider that it is inappropriate to seek an MCID for an outcome for which any occurrence is meaningful and has significant associated clinical impact and cost consequence. Nevertheless, this type of analysis was considered in the present manuscript because of the historic difficulty in establishing the cumulative impact of exacerbations and hence the value of their avoidance. It remains reasonable to contend that given the overall consequences of exacerbations on patients with COPD and the lack of treatments that reduce the frequency of exacerbations, an intervention that repeatedly has shown positive effects should be considered highly desirable.

In summary, clinical data suggest that an increased frequency of exacerbations is associated with worsening quality of life, and a more rapid decline in spirometry over time. Our analysis demonstrated a wide range of changes in the frequency of exacerbations that were associated with clinically meaningful changes in clinical outcomes. The present post-hoc analysis should be viewed cautiously. 
More data from large databases are required to continue to explore the issues raised in the present discussion.

\section{Disclosures}

Dr Anzueto had full access to all study data and takes responsibility for data integrity and accuracy of data analysis. Dr Kesten and Dr Leimer are employees of Boehringer Ingelheim.

\section{References}

1. Global Initiative for Chronic Obstructive Lung Disease. Global Strategy for the Diagnosis, Management and Prevention of Chronic Obstructive Pulmonary Disease. NHLBI/WHO workshop report. Bethesda, National Heart, Lung and Blood Institute, April 2001; Update November 2006, GOLD website. Available at: www.goldcopd.com.

2. Mannino DM, Homa DM, Akinbami LJ, Ford ES, Redd SC. Chronic obstructive pulmonary disease surveillance - United States, 1971-2000. MMWR. 2002;51:1-16.

3. Murray CGL, Lopez AD. Evidence-based health policy-lessons from the global burden of disease study. Science. 1996;274:740-743.

4. Friedman M, Witek Jr TJ, Serby CW, et al. Pharmacoeconomic evaluation of a combination of ipratropium plus albuterol compared to ipratropium alone and albuterol alone in chronic obstructive pulmonary disease. Chest. 1999;115:635-641.

5. National Heart, Lung, and Blood Institute. Morbidity and Mortality: 2002 Chart Book on Cardiovascular, Lung, and Blood Diseases Bethesda, Md: US Department of Health and Human Services, Public Health Service, National Institutes of Health; May 2002.

6. Friedman M, Hilleman DE. Economic burden of chronic obstructive pulmonary disease. Pharmacoeconomics. 2001;19:245-254.

7. Seemungal TAR, Donaldson GC, Paul EA, Bestall JC, Jeffries DJ, Wedzicha JA. Effect of exacerbation on quality of life in patients with chronic obstructive pulmonary disease. Am J Respir Crit Care Med. 1998;157:1418-1422.

8. Kanner RE, Anthonisen NR, Connett JE, for the Lung Health Study Research Group. Lower respiratory illnesses promote FEV, decline in current smokers but not ex-smokers with mild chronic obstructive pulmonary disease. Am J Respir Crit Care Med. 2001;164:358-364.

9. Plant PK, Owen JL, Elliott MW. Non-invasive ventilation in acute exacerbations of chronic obstructive pulmonary disease: long term survival and predictors of in-hospital outcome. Thorax. 2001;56:708-712.

10. Connors AF, Dawson NV, Thomas C, et al. Outcomes following acute exacerbation of severe chronic obstructive lung disease. Am J Respir Crit Care Med. 1996;154:959-967.

11. Almagro P, Calbo E, Ochoa de Echaguen A, et al. Mortality after hospitalization for COPD. Chest. 2002;121:1441-1448.

12. Soler-Cataluna JJ, Martinez-Garcia MA, Roman Sanchez P, et al. Severe acute exacerbations amd mortality in patients with chronic obstructive pulmonary disease. Thorax. 2005;60:925-931.

13. Miravitlles M, Murio C, Guerrero T, Gisbert R, on behalf of the DAFNE study group. Pharmacoeconomic evaluation of acute exacerbations of chronic bronchitis and COPD. Chest. 2002;121:1449-1455.
14. Jaeschke R, Singer J, Guyatt GH. Measurement of health status. Ascertaining the minimally clinically important difference. Control Clin Trials. 1989;10:407-415.

15. Jones PW, Quirk FH, Baveystock CM, Littlejohns P. A self-complete measure of health status for chronic airflow limitation. Am Rev Respir Dis. 1992;145:1321-1327.

16. Jones PW. Interpreting thresholds for a clinically significant change in health status in asthma and COPD. Eur Resp J. 2002;19:398-404.

17. Disse B, Speck GA, Rominger KL, Witek TJ, Hammer R. Tiotropium (Spiriva): mechanistical considerations and clinical profile in obstructive lung disease. Life Sci. 1999;64:457-464.

18. Casaburi R, Mahler DA, Jones PW, Wanner A, San Pedro G, ZuWallack RL, et al. A long-term evaluation of once-daily tiotropium in chronic obstructive pulmonary disease. Eur Respir J. 2002;19: 217-224.

19. Vincken W, van Noord JA, Greefhorst APM, Bantje ThA, Kesten S, Korducki L, et al. Improved health outcomes in patients with COPD during 1 yr's treatment with tiotropium. Eur Respir J. 2002;19: 209-216.

20. Brusasco V, Hodder R, Miravitlles M, Korducki L, Towse L, Kesten S. Health outcomes following treatment for six months with once daily tiotropium compared with twice daily salmeterol in patients with COPD. Thorax. 2003;58: 399-404.

21. O'Donnell D, Flüge T, Gerken F, et al. Effects of tiotropium on lung hyperinflation, dyspnoea and exercise tolerance in COPD. Eur Respir J. 2004;23:832-840.

22. Maltais F, Hamilton A, Marciniuk D, et al. Improvements in symptomlimited exercise performance over eight hours with once-daily tiotropium in patients with COPD. Chest. 2005;128:1168-1178.

23. Dusser D, Bravo ML, Iacono on behalf of the MISTRAL study group. The effect of tiotropium on exacerbations and airflow in patients with COPD. Eur Resp J. 2006;27:547-555.

24. Niewoehner DE, Rice K, Cote C, et al. Prevention of exacerbations of chronic obstructive pulmonary disease with tiotropium, a once-daily inhaled anticholinergics bronchodilator. Ann Intern Med. 2005;143:319-326.

25. Standardization of spirometry - 1994 update: statement of the American Thoracic Society. Am J Respir Crit Care Med. 1995;152: S77-S120.

26. Mahler DA, Weinberg DH, Wells CK, Feinstein AR. The measurement of dyspnea: contents, interobserver agreement and physiologic correlates of two new clinical indexes. Chest. 1984;85:751-758.

27. Witek TJ, Mahler DA. Meaningful effect size and patterns of response of the transition dyspnea index. $J$ Clin Epidemiol. 2003;56(3): $248-255$.

28. Witek TJ, Mahler DA. Minimal important difference of the transition dyspnoea index in a multinational clinical trial. Eur Respir $J$. 2003;21(2):267-272.

29. Rodriquez-Roisin R. Towards a consensus definition for COPD exacerbations. Chest. 2000;117:398S-401S.

30. Celli BR, MacNee W and committee members. Standards for the diagnosis and treatment of patients with COPD: a summary of the ATS/ERS position paper. Eur Resp J. 2004;23:932-946.

31. Donaldson GC, Seemungal TAR, Bhowmik A, Wedzicha JA Relationship between exacerbation frequency and lung function decline in chronic obstructive pulmonary disease. Thorax. 2002;57: $847-852$.
International Journal of COPD

\section{Publish your work in this journal}

The International Journal of COPD is an international, peer-reviewed journal of therapeutics and pharmacology focusing on concise rapid reporting of clinical studies and reviews in COPD. Special focus is given to the pathophysiological processes underlying the disease, intervention programs, patient focused education, and self management protocols.

\section{Dovepress}

This journal is indexed on PubMed Central, MedLine and CAS. The manuscript management system is completely online and includes a very quick and fair peer-review system, which is all easy to use. Visit http://www.dovepress.com/testimonials.php to read real quotes from published authors. 